\title{
Personal Development Peculiarities on Gender Perspective in Georgia
}

\author{
Natalia Kharadze \\ $\mathrm{PhD}$ in Economics, CEO of HPML, Professor of TSU \\ Ekaterine Gulua \\ $\mathrm{PhD}$ in Economics, Manager of HPML, Professor of TSU
}

\begin{abstract}
Receiving appropriate education and occupying a place in the labor market is not easy. The barriers that a person has to overcome can be solved systematically by personal development and joint efforts of universities or an organization. We must take any action that leads to success and act in spite of the fact that this action may not be a great pleasure. Everyone has aspirations. It is important for people to link these skills to the field of their activity. When you love your own job and you are prone to it, you have more chance of achieving success with less effort. Being successful is the need for any person, but not everyone can achieve it. People differ from each other by their goals, to what extent they are ready to overcome the barriers to achieving a goal, how they can survive problems, contradictions. Naturally, achieving a goal requires great work and support. Failures often happen while trying to succeed. At this time, it is necessary to overcome pessimism and it is important to develop optimism by analyzing the causes of the failure. 'Hard work' does not mean 'effective work'. The most important thing is to use the resources wisely and achieve the goal by effective work. Today there are many methods to help people discover their abilities, with the help of this method they improve their communication skills, increase their labor productivity and achieve success by spending less energy. One of these methods is Augusto Boal's method. What is young people's attitude to personal development, how much support do they feel from the university and what expectations do they have from their organizations, how well are they determined, what is their attitude towards life - positive or negative; how can they deal with stress, develop creative thinking, develop leadership skills? - These issues have become an interesting topic for our laboratory, which are functioning at the Faculty of Economics and Business at Ivane Javakhishvili Tbilisi State University. The laboratory has conducted a number of studies, which have already been published in various magazines or at conferences. The studies focused on students' time budget, organizational culture and conflicts in an organization, as well as the assessment criteria for professors.
\end{abstract}

Keywords: Organization, Humane Resources Managment, Personal Development, Gender.

\section{Introduction}

Receiving appropriate education and occupying a place in the labor market is not easy. The barriers that a person has to overcome can be solved systematically by personal development and joint efforts of universities or an organization (Gulua, Ekaterine;, 2014) (Gulua, Ekaterine;, 2011). We must take any action that leads to success and act in spite of the fact that this action may not be a great pleasure.

Everyone has aspirations. It is important for people to link these skills to the field of their activity. When you love your own job and you are prone to it, you have more chance of achieving success with less effort (Amkoladze, G; Gabrichidze, A; Giorgobiani , M; Zedgenidze M; Kharadze , N;, 2014). Being successful is the need for any person, but not everyone can achieve it. People differ from each other by their goals, to what extent they are ready to overcome

the barriers to achieving a goal, how they can survive problems, contradictions. Naturally, achieving a goal requires great work and also support.

Failures often happen while trying to succeed. At this time, it is necessary to overcome pessimism and it is important to develop optimism by analyzing the causes of the failure. 
'Hard work' does not mean 'effective work' (Amkoladze , G; Gabrichidze, A; Giorgobiani , M; Lomsadze-Kutchava, M; Kharadze, $\mathrm{N} ;$, 2014) . The most important thing is to use the resources wisely and achieve the goal by

effective work. (Gulua, Ekaterine, 2012) .Today there are many methods to help people discover their abilities, with the help of this method they improve their communication skills, increase their labor productivity and achieve success by spending less energy. (Gulua, Ekaterine, 2013). (Gulua, Ekaterine, 2012), One of these methods is Augusto Boal's method (Boal, Augusto;, 2008) .

What is young people's attitude to personal development, how much support do they feel from the university

and what expectations do they have from their organizations, how well are they determined, what is their attitude towards life - positive or negative; how can they deal with stress, develop creative thinking, develop leadership skills? - These issues have become an interesting topic for our laboratory which is functioning at the Faculty of Economics and Business at Ivane Javakhishvili Tbilisi State University.

The laboratory has conducted a number of studies, which have already been published in various magazines or at conferences. The studies focused on students' time budget (Ekaterine, Gulua; Natalia, Kharadze, 2017), (Kharadze, Natalia; Gulua, Ekaterine, 2016), (Kharadze, Natalia; Gulua, Ekaterine, 2017), (Kharadze, Natalia; Gulua, Ekaterine; Duglaze, Davit, 2017), (Kharadze, Natalia; Gulua, Ekaterine, 2017)); organizational culture (Gulua, Ekaterine; Kharadze, Natalia, 2014), (Gulua, Ekaterine; Kharadze, Natalia;, 2018), and conflicts (Kharadze, Natalia; Gulua, Ekaterine;, 2018), in an organization, as well as the assessment criteria for professors. (Kharadze, Natalia; Gulua, Ekaterine;, 2018), (Gulua, Ekaterine, 2017), (Gulua, Ekaterine; Mikaberidze, Akaki, 2015). This time again our research object is TSU students. The questionnaire was designed which included 28 questions and 112 options for answer. 500 respondents were interviewed and the data was processed by the SPSS program. Several hypotheses have been developed and based on interesting results we have received some recommendations and made conclusions. Our laboratory will continue to study interesting issues in this direction. It will be desirable to involve foreign colleagues and implement joint projects.

The survey included 500 randomly selected students, out of which the first year students constitute $16.6 \%$ of the respondents. Among them females are 6,2\% and men - 10,4; The second year students are $20 \%$. Among them females $10,8 \%$ and males - 9,2\%; The third year students are $21.8 \%$. Among them females $-10,2 \%$ and men $-11,6 \%$; The fourth year students are $18.8 \%$, females - $12 \%$ and males - $6,8 \%$; Additional semester students are $2,8 \%$, females - $1 \%$ and males - 1.8\%; The first year students of the surveyed MA students constitute 18\%, among them females are $10,4 \%$ and males - 7,6\%; The second year MA students are 1,8\%, among them females are $1.4 \%$ and males - $4 \%$. The MA students of additional semesters are all females $(2 \%)$ (see Diagram 1 ).

\section{Diagram 1 Your studying semester:}

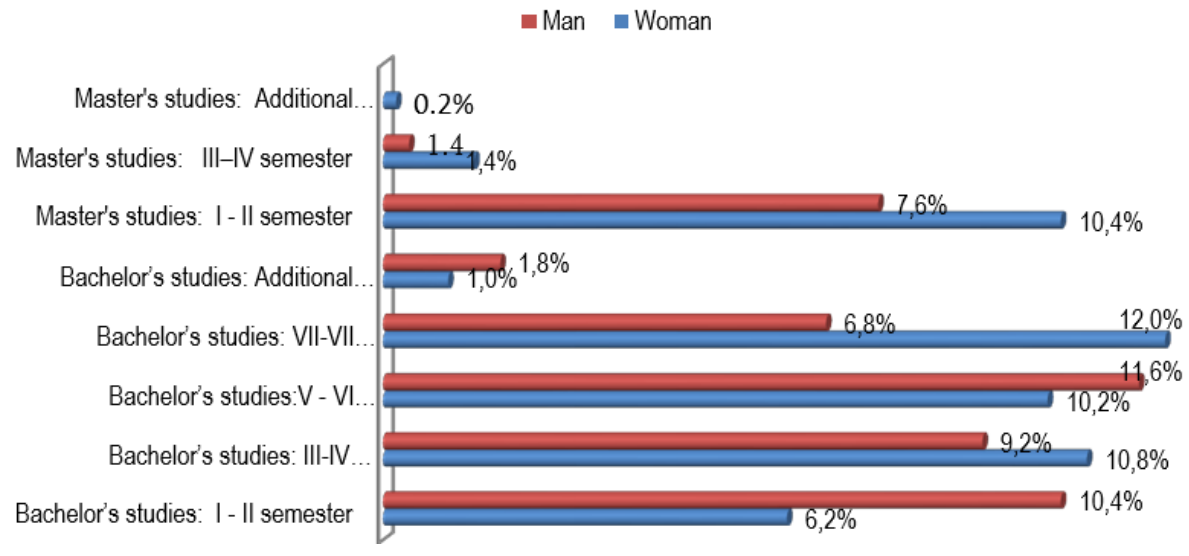

As a result of the study, the majority of the respondents in women as well as in men are mostly employed in enterprise (private commercial) sector, particularly, $41.6 \%$ of the interviewed respondents are men and $35.8 \%$ are female 
respondents. Followed by the state (public) sector where the respondents are distributed respectively : in the following proportions: $6,8 \%$ and $7,8 \%$, the smallest number of respondents are represented in non-profit (non-commercial) sectors

(see Schedule 1). These indicators may show that the government has been promoting private sector development recently in Georgia. Also, students' desire to work in the private sector is quite high.

\section{Schedule 1. Place of your employment according to a sector}

\begin{tabular}{|l|l|l|l|l|}
\hline $\begin{array}{l}\text { Place of your employment according } \\
\text { to a sector }\end{array}$ & $\begin{array}{l}\text { State } \\
\text { (public) }\end{array}$ & $\begin{array}{l}\text { Entrepreneurial (private, } \\
\text { commercial) }\end{array}$ & $\begin{array}{l}\text { Non-entrepreneurial (non- } \\
\text { profit) }\end{array}$ & Total \\
\hline Woman & $7.8 \%$ & $41.6 \%$ & $2.8 \%$ & $52.2 \%$ \\
\hline Man & $6.8 \%$ & $35.8 \%$ & $5.2 \%$ & $47.8 \%$ \\
\hline Total: & $14.6 \%$ & $77.4 \%$ & $8.0 \%$ & $100.0 \%$ \\
\hline
\end{tabular}

The time management of the employed students is quite difficult and it has been revealed in previous studies that were related to MA students. This study showed that even in the case of undergraduates, the level of full-time employees is high. In particular, $23.8 \%$ women and $24,6 \%$ men are employed fully in the stuff; At the half-rate,

respectively, $18.4 \%$ and $10,8 \%, 10 \%$ and $12,4 \%$-with a free schedule (See Diagram 2 ).

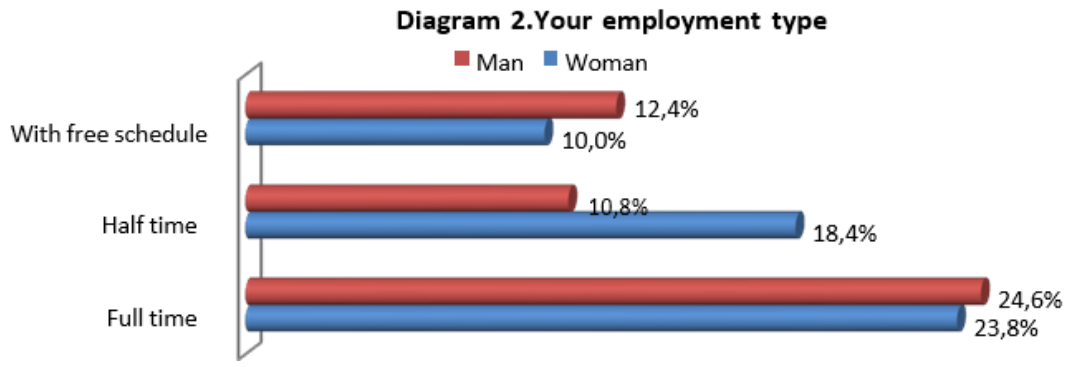

When it comes to employment, it is important to know the reason for students' choice and how much they are inclined to specific activity. Previous studies have shown that the main purpose of students employment was the material situation. The students agreed to a little payment to cover the tuition fees. This study showed that $28.0 \%$ of the women and $28 \%$ of the men report that they have a natural talent in their specialty and are prone to work, $21.6 \%$ women and $16,0 \%$ men are partially inclined towards their job, respectively, 2,6\% and 3,6\% admit that they do not have a natural inclination towards their activity (see Diagram 3 ). With little difference but still women are more likely to choose a work that they are prone to, this fact can be explained by many reasons, one of them is that men are still considered to be the main force of the family in Georgia, and, therefore, the latter are ready for any kind of activities.

Diagram 3. Do you feel you have a natural talent in your specialty

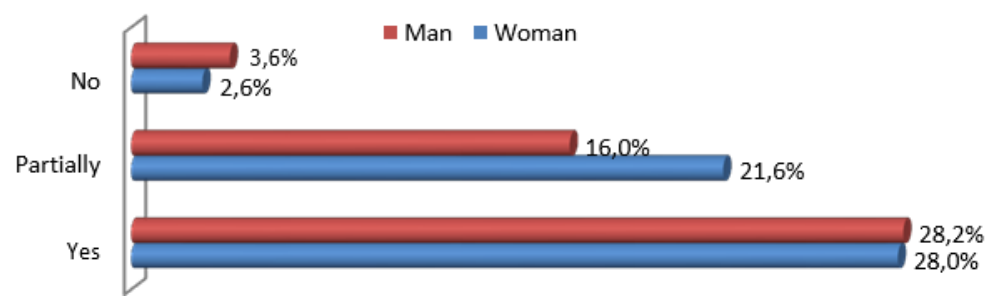

The inclination to the profession itself leads to love for it. It's a pleasure to do a lovely job. The research shows that $34 \%$ of the women and $32.6 \%$ of the men have love towards their profession, $15.8 \%$ women and $12.2 \%$ men "partly" love their profession. It can be considered as a good indicator that only $2,4 \%$ women and 3,0\% men have no love for their profession, which means that they have made the right choice (see Diagram 4). 
Diagram 4. Do you like you're your profession?

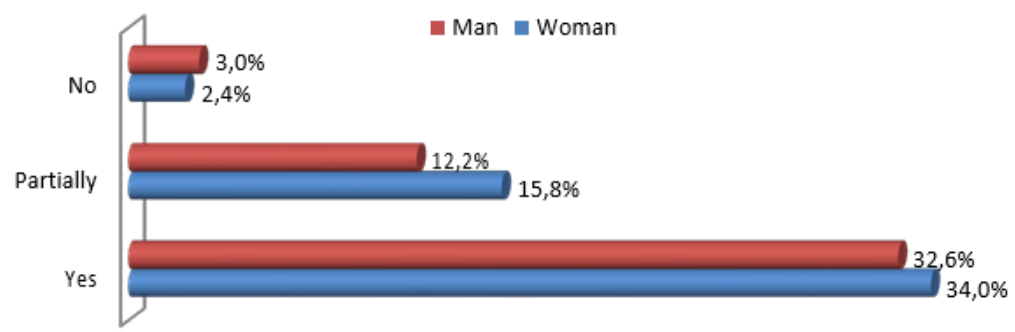

$18 \%$ women of the respondents believe that their profession is largely creative and $23 \%$ men think the same way, while $34.2 \%$ women consider their profession as logical, this indicator in men is $24.8 \%$ (see Diagram 5).

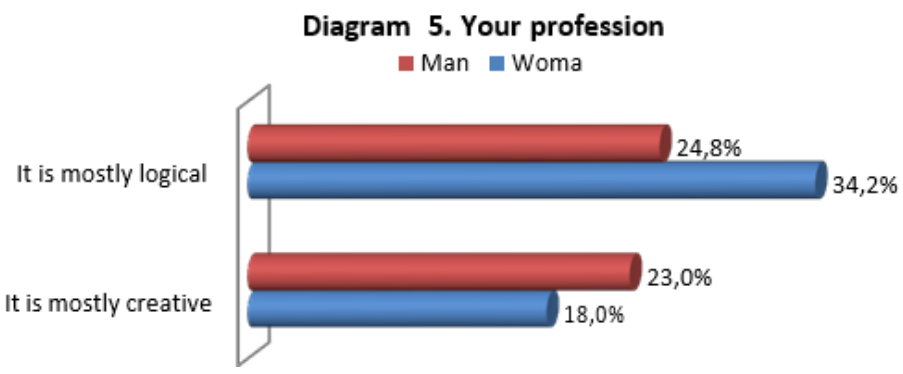

It is interesting to see if the respondents are employed by their specialty. The study showed that $28,6 \%$ female and $25 \%$ male respondents are employed by their specialty; $11,8 \%$ of the women and $12.8 \%$ of the men believe that they are partially employed by their specialty, $11.8 \%$ of the women and $10 \%$ of the men are not employed by the specialty. In this regard the difference of any substantive nature was not observed by gender (see Diagram 6).

\section{Diagram 6. Are you employed by your specialty}

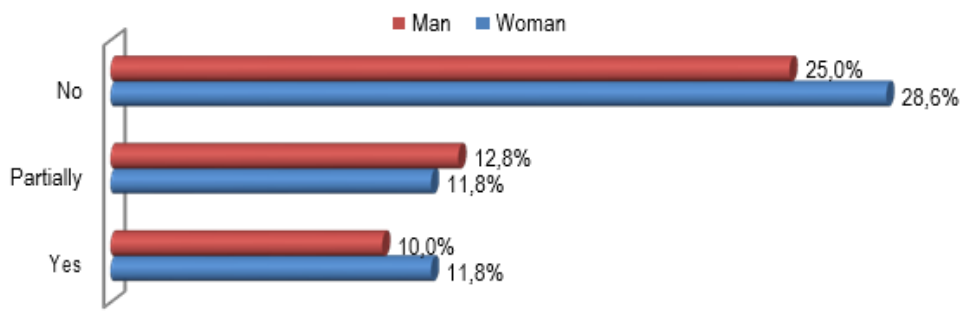

The majority of the respondents, as we have seen, are employed by their specialty. It is, therefore, interesting to see how the respondents are prepared to use theoretical knowledge in practice and whether they use their knowledge in practice. The common opinion that the university gives knowledge that they do not need in practice has been rejected. As a result of the research, $3,8 \%$ women and $3,2 \%$ men report that the theoretical knowledge which they received is mostly unusable, are partially utilized by $27.6 \%$ women and $23,2 \%$ men, the positive response was shown by $20.8 \%$ women and $21,4 \%$ men (see Diagram 7 ). 
Diagram 7. Do you think you have theoretical knowledge that you will use in practice or are you using it now?

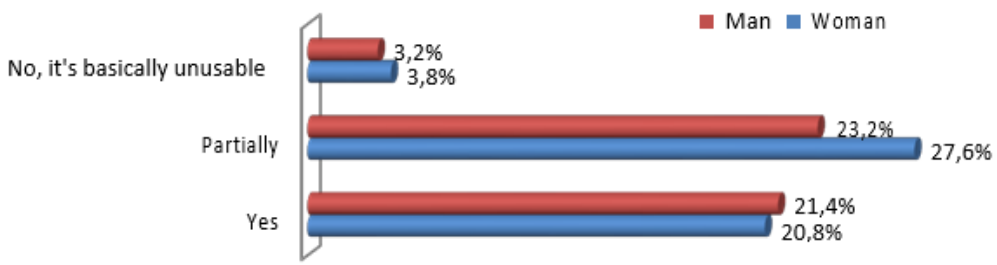

It is interesting to know what a supporting action plan is designed for employed students by organizations. Are they interested in taking care of young employees and in what way do they express it? The study has found that $24 \%$ women and $21.2 \%$ men are encouraged by the organization to combine working with studying, $13.4 \%$ women and $12.2 \%$ men often have the benefits, $11 \%$ women and 10,2\% men responded "sometimes", a negative answer was recorded by $3.8 \%$ women and $4,2 \%$ men. No discrimination is observed in this regard (see Diagram 8 ).

Diagram 8. Does you organization help you with your study at the

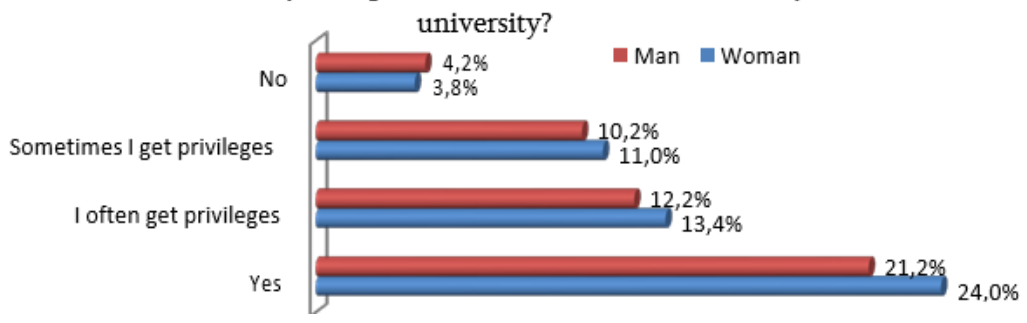

The study found that the individual development plan for employees in most organizations does not exist or is just written on the paper. Only $13.2 \%$ women and $15.4 \%$ men confirm the existence of such kind of plan, the formal nature of the plan is indicated by $15,2 \%$ women and $17 \%$ men, and those who have not heard about such a plan are $23.8 \%$ women and $15.4 \%$ men (see Diagram 9).

Diagram 9. Have you made your personal development plan with

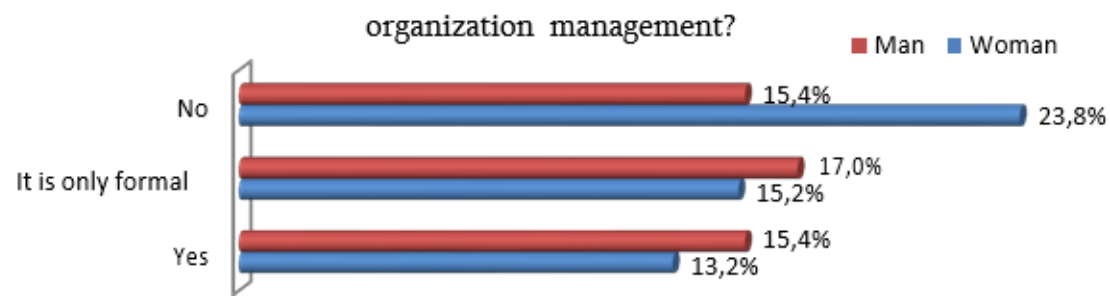

The fact that organizations do not have individual development plans for the staff, has also been proved by the fact that less attention is paid to raising their qualification by trainings. $25,4 \%$ women and $16.8 \%$ men indicate that their qualification raising is not funded by organization, answer "rarely" was indicated by 10,4\% women and 10.8\%; The answer "often" was indicated by $7,4 \%$ women and $8,2 \%$ men and a positive response only by $9.2 \%$ women and $12 \%$ men (see Diagram 10). 


\section{Diagram 10. Do you raise your qualification with your organization funding? (Trainings, paying training fee)}

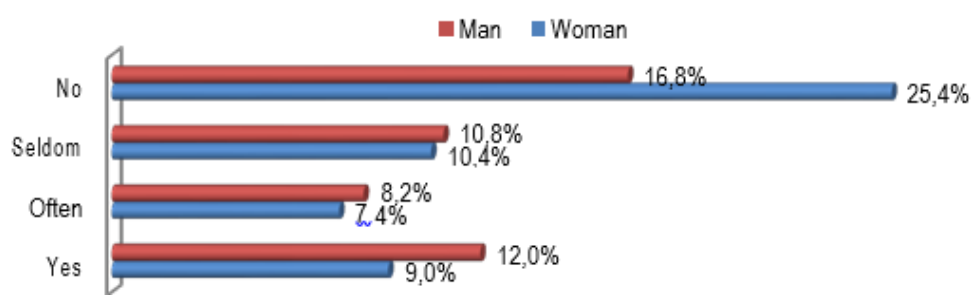

It is important to know what kind of payment policies are in the organization and whether the principle of fairness is protected. As the survey has shown $18 \%$ women and $20 \%$ men are satisfied with their own pay and consider that it are relevant to their work. The answer "rarely" was indicated by $15.8 \%$ women and $16,2 \%$ men, $18,4 \%$ women and $11,6 \%$ men are completely dissatisfied (see Dagram 11).

Diagram 11. Are you satisfied with your salary (Do you think it is

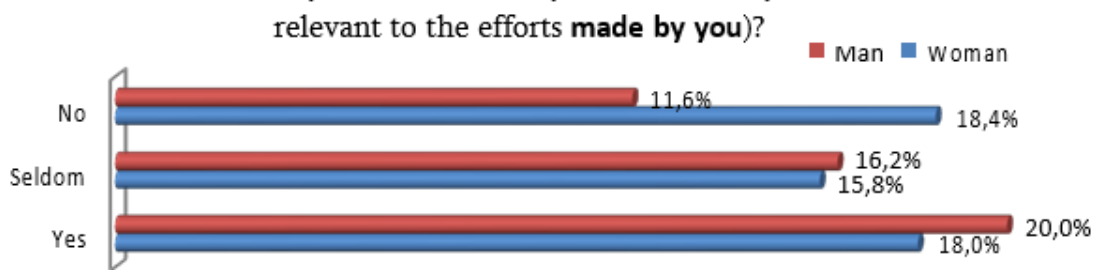

Regardless of the legislative requirement the overtime work to be paid, not to say anything about the moral side, unfortunately, the employer is less likely to pay it. $23.4 \%$ women and $23.6 \%$ men positively responded to this question, "rarely" and "never" were answered by $8.2 \%$ women and $20 \%$ men and $20.6 \%$ women and $15.6 \%$ men responded negatively to this question (see Diagram 12). Naturally, such an attitude towards young employees will cause a feeling of dissatisfaction and often makes them think they are victims of discrimination. The compensation level is also a problem.

\section{Diagram 12. Have you received a compensation for working overtime?}

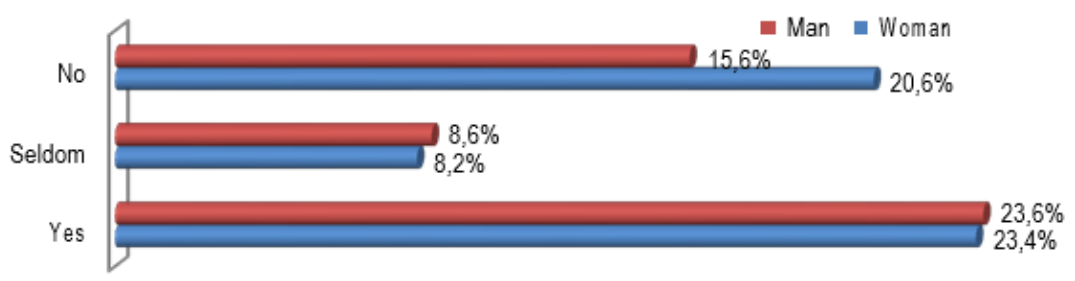

Under the current prices, when the national currency devaluation takes place, $1500 \mathrm{GEL}$ is not enough quantity to support the family, pay taxes and eat properly. In spite of this, only $0.8 \%$ of women and $4,4 \%$ of the men reported that they are paid more than $1500 \mathrm{GEL}(550 €)$. From 30 to $500 \mathrm{GEL}$, we can assume that, it is equivalent to slavery, if an employee works full-time, $49.2 \%$ women and $41.2 \%$ men confirmed to have this kind of salary (see Diagram 13). As we can see, the remuneration for existence is a destiny only for outstanding ones. 


\section{Diagram13. Your compensation is:}

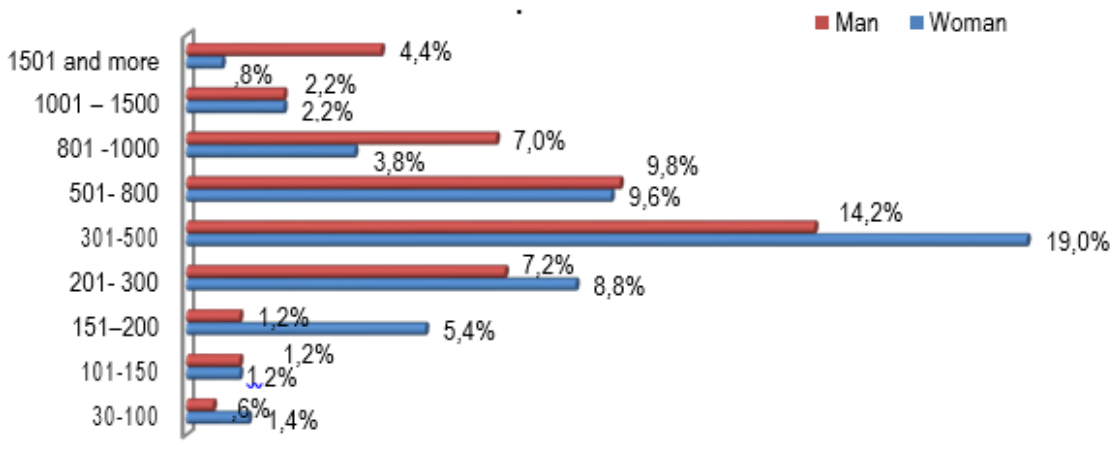

What is the feeling of young people in terms of realizing their own goals, what are their goals and if they realize their abilities? The survey found that 7,6\% women and $9.8 \%$ men have a satisfactory attitude, mostly negative and categorical answer were given by $23.8 \%$ women and $18.2 \%$ men (see Diagram 14). Women's pessimism is slightly but still high. It is no surprise, in today's society, men have a much greater chance of progress than women and this trend is observed in all areas.

\section{Diagram 14. Do you think that your organization is the place where you} can realize your potential

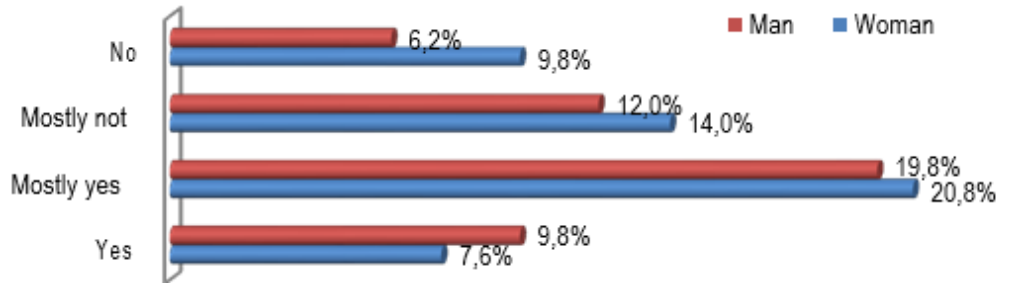

It is interesting to note that despite the above-mentioned position, people are unable to realize their capabilities, slightly but still most of the percentages indicate that they are willing to stay in the organization, namely $9,2 \%$ women and $11,4 \%$ men. It is strongly determined that $16.6 \%$ women and $16.4 \%$ men won't stay at the organization, $25.4 \%$ of the women and $17.8 \%$ of the men believe that it is a temporary job (see Diagram 15). Sadly, this tendency is not healthy, it's hard to work in the organization where you do not feel like a family member. This kind of attitude can affect their productivity.

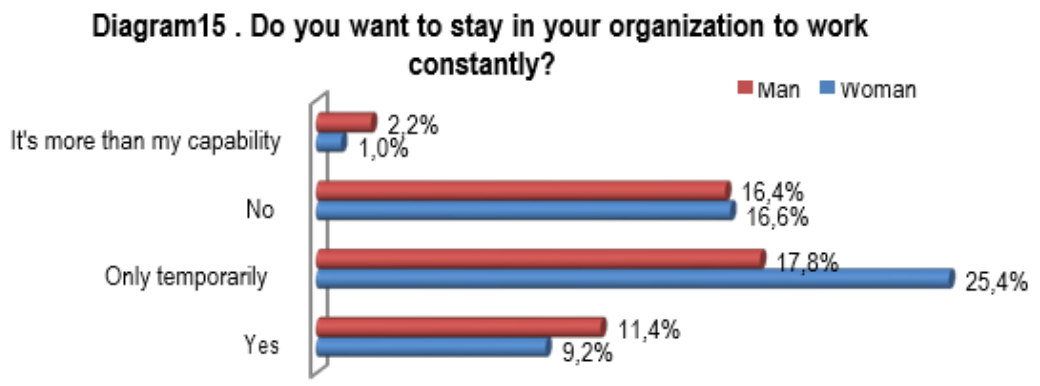

It is important to know how much the young people feel that their job motivates their career progression. The total hopelessness of career growth was observed by $20.4 \%$ women and $16.8 \%$ men, $11.8 \%$ of the women and $11.8 \%$ men say that the organization does not have the appropriate potential, $20 \%$ women and $19.2 \%$ of the men have a hope for career advancement (see Diagram 16). 


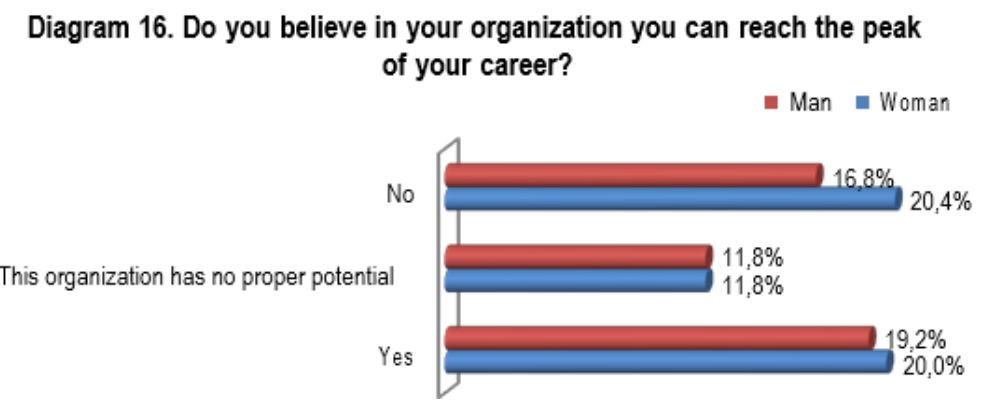

Labor productivity of any employee depends on the climate of the organization which is reflected on their relationships and causes tensions and conflicts or positive relationships. $28 \%$ women and $27.2 \%$ men indicate that there is a positive environment in the organization, $21.8 \%$ women and $19.6 \%$ men think that the environment is satisfactory, and only $2,4 \%$ women and $1 \%$ men think that there are negative and conflict situations in the organization (see Diagram 17).

\section{Diagram 17. The relationships in your organization are}

Negative (There are frequent conflicts, tensions)

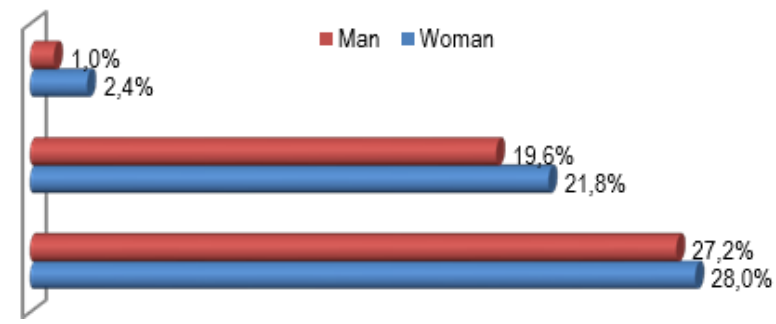

Non-formal relationships also have a positive effect on the improvement of organizational atmosphere. Rarely this attitude was observed by $26.8 \%$ women and $22.6 \%$ men, existence of formal relationships was reported by only $25.4 \%$ women and $25.2 \%$ men (see Diagram 18).

Diagram 18. Do you have informal relationships with organization members?

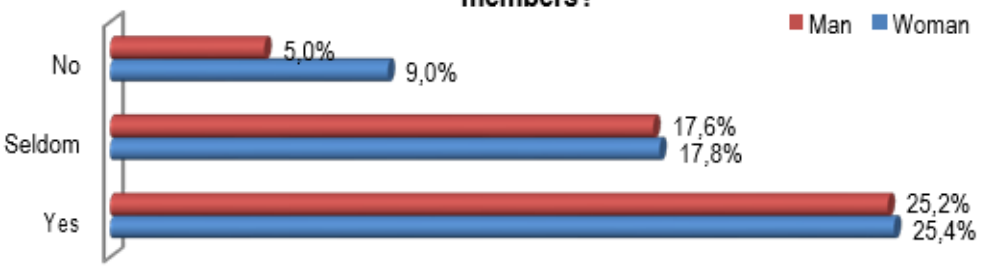

The official and formal relationship in the organization is reported by $9,8 \%$ of the women and $11 \%$ of the men, friendly relationships - by with $40.4 \%$ women and $35.8 \%$ men (see Diagram 19). Although the level of informal connections that lead to getting staff closer is not high, conflict situations are less frequent and such facts are indicated by $2 \%$ women and $1 \%$ men. As expected, women are more involved in conflict situations. 


\section{Diagram 19. Relationships while working in the organization are}

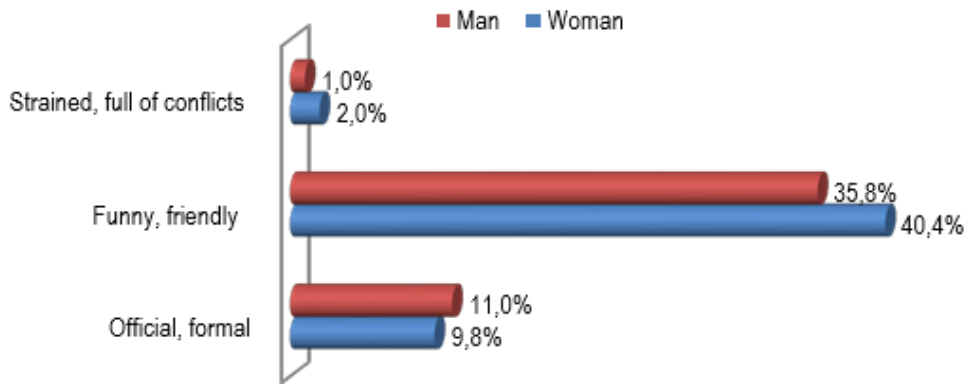

Without mutual aid and knowledge sharing it is impossible to develop a person as well as organization (see Diagram 20). $21 \%$ women and $18.2 \%$ men gave negative responses. $31.2 \%$ women and $29.6 \%$ men feel the support from the employees and the willingness to share their knowledge. In total this number is $59,8 \%$ of the interviewed respondents which is not alarming.

\section{Diagram 20. Are colleagues ready to share their knowledge with you?}

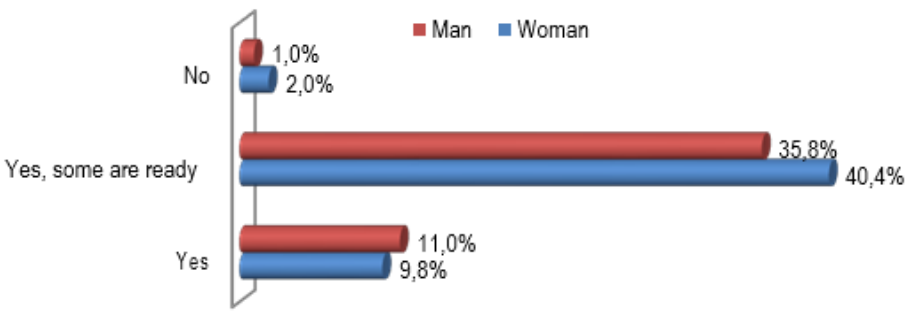

It is important for each member of the organization to feel safe and have a sense of justice (see Diagram 21) $21.2 \%$ women and $21.2 \%$ men have a strongly positive position and $2,4 \%$ women and $1,8 \%$ men have a strongly negative position. The rest of the "mostly yes" and "mostly not" answers I think are less sincere and it's hard to attach them to any position.

\section{Diagram 21. Is your organizational situation fair?}

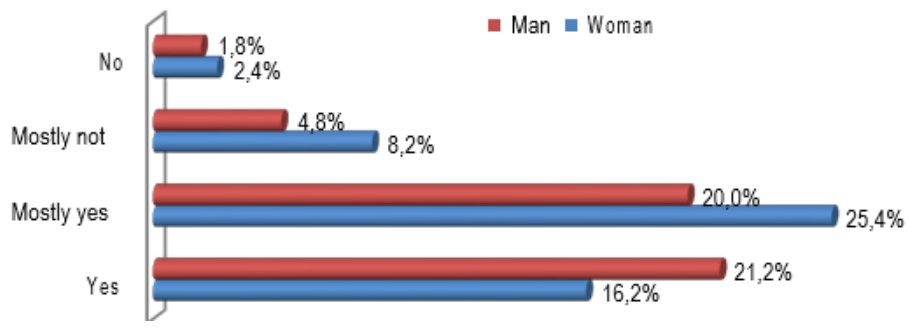

The silence on existing problems indicates an unhealthy environment (see Diagram 22). It is pleasant to say that only $3,4 \%$ women and $2 \%$ men are avoiding talking about the problem. $16,4 \%$ of the women and $13 \%$ of the men can easily talk to the manager about problems, $32.4 \%$ women and $32.2 \%$ men speak freely at all levels. Communicating with the manager seems to be much easier for the women and their communication skills are better. 


\section{Diagram 22. About the problems related to the case}

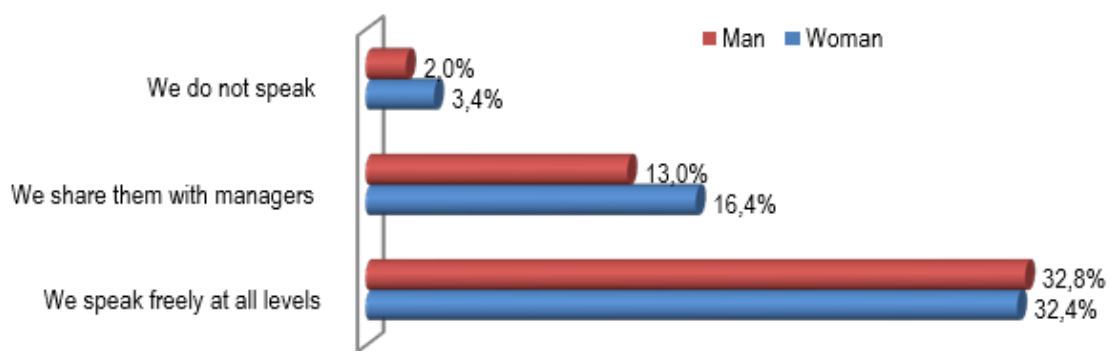

In any organization and establihment it is important for people to recognize each other's psychological recognition. Each member's expectation is the results of their work and their talents to be respected (See Diagram 23). Such approach and values increase employee's motivation which is positively reflected on the results of the organization and contributes to the growth of the person. It is pleasant to find that $35.6 \%$ female and $36.4 \%$ male respondents think that their talent in the organization is appreciated.

\section{Diagram 23. Are talented people in your organization respected}

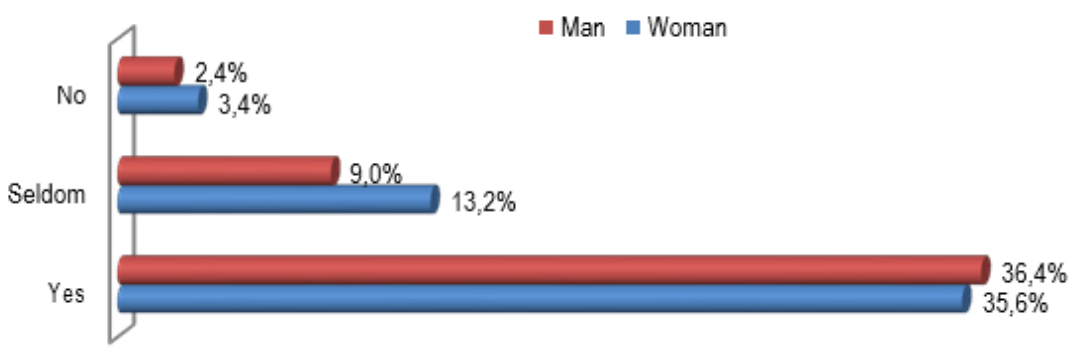

As a result of the assessment of the survey, such an impression was made that respondents positively evaluated their jobs. However, the answer to some of the questions gave us a different picture (see Diagram 24). In particular, only $23.4 \%$ women and $22.4 \%$ men like their own job. This is less than the half of the interviewed respondents. As it seems a lot of work is needed to be done each employee to feel safe, secure and comfortable at work.

Diagram 24. Do you like your job?

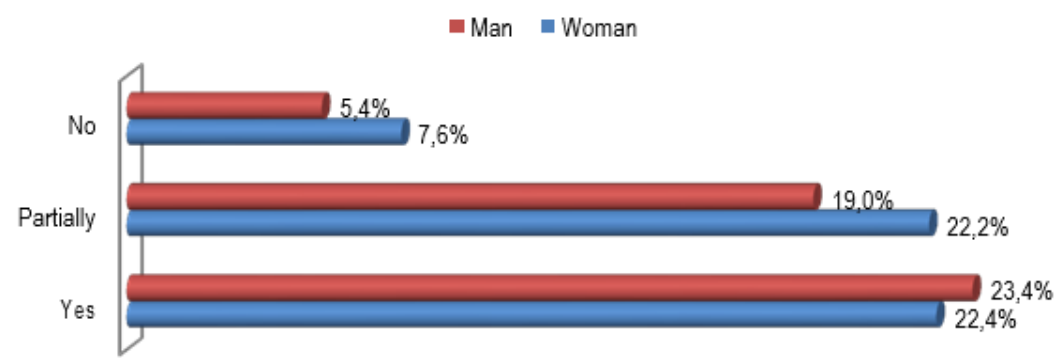

The preliminary hypothesis has been verified by statistical methods. In particular, we used Pearson correlation analysis; the Chi-squared test for testifying the reliability of the connections between variables and the linear regression, in particular, the ANOVA test.

H1: Variable - Q28 (gender) affects variables:

Q11 (Is the environment in your organization fair?); 
Q14 (With the management of the organization have you developed your personal development plan); Q22 (Are you satisfied with pay (Do you think that it is relevant to the effort you made)?

Q25 (The amount of pay).

The formed hypothesis suggested that gender (Q11) affects the perception of justice in the employer organizations (Q11), whether they have developed personal development plan with the help of the organization (Q14), gender affects payment (Q25), gender affects the perception that the payment is relevant to the effort made by an employee (Q22).

To prove the hypothesis we have introduced Pearson Correlative Analysis Test, which confirmed the existence of correlation between variables. However, the connection between Q28, Q11, Q14, Q22, variables is very weak (ranging from [-0,2 to 0.2), while the connection between Q28 and Q25 is relatively weak (ranging from [-0.5 to 0.5] (See Table 2)

Table 2. Correlations

\begin{tabular}{|c|c|c|c|c|c|c|}
\hline & & Q28 & Q11 & Q14 & Q22 & Q25 \\
\hline Q28 & $\begin{array}{l}\text { Pearson Correlation } \\
\text { Sig. (2-tailed) }\end{array}$ & 1 & $-.128^{* *}$ & $-.124^{* *}$ & $-.112^{*}$ & $.216^{* *}$ \\
\hline & $\mathrm{N}$ & 500 & 500 & 500 & 500 & 500 \\
\hline Q11 & Pearson Correlation & $-128^{\star *}$ & 1 & $.260^{* *}$ & $.402^{* *}$ & $-.096^{*}$ \\
\hline & Sig. (2-tailed) & .004 & & .000 & .000 & .032 \\
\hline & $\mathrm{N}$ & 500 & 500 & 500 & 500 & 500 \\
\hline Q14 & Pearson Correlation & $.124^{* *}$ & $.260^{* *}$ & 1 & $320^{* *}$ & $-155^{* *}$ \\
\hline & Sig. (2-tailed) & .005 & .000 & & .000 & .001 \\
\hline & $\mathrm{N}$ & 500 & 500 & 500 & 500 & 500 \\
\hline Q22 & Pearson Correlation & $-112^{*}$ & $.402^{* *}$ & $320^{* *}$ & 1 & $-348^{* *}$ \\
\hline & Sig. (2-tailed) & .013 & .000 & .000 & & .000 \\
\hline & $\mathrm{N}$ & 500 & 500 & 500 & 500 & 500 \\
\hline Q25 & Pearson Correlation & $216^{* *}$ & $-.096^{*}$ & $-.155^{* *}$ & $-.348^{\star *}$ & 1 \\
\hline & Sig. (2-tailed) & .000 & .032 & .001 & .000 & \\
\hline & $\mathrm{N}$ & 500 & 500 & 500 & 500 & 500 \\
\hline
\end{tabular}

The Chi-squared test revealed that only two variables - the relationship between gender (Q28) and the amount of compensation (Q25) is reliable or is less than 0,05 (see Table 3).

Table 3. Q28* Q25 Chi-Square Tests

\begin{tabular}{|l|l|l|l|}
\hline Table Chi 3 & Value & df & Asymp. Sig. (2-sided) \\
\hline Pearson Chi-Sauare & $25517 \mathrm{a}$ & 8 & .000 \\
Likelihood Ratio & 37.957 & 8 & .000 \\
Linear-by-Linear Association & 23.222 & 1 & .000 \\
N of Valid Cases & 500 & & \\
\hline
\end{tabular}

cells $(5.6 \%)$ have expected count less than 5 . The minimum expected count is 4.78 . 
By the analysis of the linear regression the ANOVA test has shown that Q28, Q11, Q14, Q22, Q25 model is reliable, because the sigma is less than 0,005 . This test has also revealed that the preferred one among dependent variables is the amount of the pay - Q25 variable (see Table 4. ANOVA).

Table 4. Linear Regression ANOVAa

\begin{tabular}{|c|c|c|c|c|c|c|}
\hline \multirow{4}{*}{1} & & Sum of Squares & df & Mean Square & $\mathrm{F}$ & Sig. \\
\hline & Regression & 7.869 & 4 & 1.967 & 8.331 & $.000^{\mathrm{b}}$ \\
\hline & Residual & 116.889 & 495 & .236 & & \\
\hline & Total & 124.758 & 499 & & & \\
\hline
\end{tabular}

Dependent Variable:Q28

Predictors: (Constant), Q25, Q11, Q14, Q22

The fact that some of the women and the men among respondents, not so small in number, who think that they do not have a natural talent in their profession, hinders their development. It is important to work with adolescents in order to find out what aspirations they have and to develop young ones in this direction. As it seems in Georgia parents' influence is still big who make decisions instead of their children.

Lower than average negative attitude towards the profession was observed by both sexes. Naturally, this indicator can be caused by the lack of talent and inclination. This problem can be solved at the working place, if an employee gets interested in what part of the task has to be executed by the employee it will be more pleasant to do. Delegating process should be implemented by observing the rules.

It is important for the organization to take care of each employee's personal development plan and it should be done by a mutual agreement.

Sharing knowledge and experience should be developed as the culture and positive character of the organization.

The fact that a large part is not inclined towards activities that they are doing is not surprising, they have to work hard and spend extra time to perform the task. It is important for the organization to pay extra compensation for such individuals to increase their motivation.

Every employee should feel that their work is appreciated and they can be promoted on their professional career level. Without elaborating a career management policy an employee's personal development cannot be accomplished.

\section{Bibliography}

[1] Amkoladze , G; Gabrichidze, A; Giorgobiani , M; Lomsadze-Kutchava, M; Kharadze, N;. (2014). Globalization of research of factors of success of Georgian business leaders. Modern Issues of Medicine and Management Quarterly international refered, peer-reviewed Collected Scientific Works, 146-151.

[2] Amkoladze, G; Gabrichidze, A; Giorgobiani , M; Zedgenidze M; Kharadze , N;. (2014). Leadership development features in conditions of global economics. Modern Issues of Medicine and Management Quarterly international refereed, peer-reviewed Collected Scientific Works , 141-145.

[3] Boal, Augusto;. (2008). Theatre of the oppressed. London: PLUTO PRESS.

[4] Economics and Business, Business and Economics Refereed and Reviewed International Scientific and Practical Journal of the Faculty of Economics and Business, Ivane Javakhishvili Tbilisi State University , pp. 112-132.

[5] Ekaterine, Gulua; Natalia, Kharadze. (2017). Impact of Time Management on Personal Development of Master's Degree Students. ICSS XXIII, (pp. 110-118). Vienna.

[6] Gulua, Ekaterine. (2017 6mol April-June Volume X, N2). Modern Challenges of Higher Education.

[7] Gulua, Ekaterine. (2012). The Post-Crisis Contextual Decisions in Business Organisations. Proceedings of the International Scientific-Practical Conference: "Globalization, Contemporary Problems of International Business and Development Trends" (pp. 245-250). Tbilisi: Universal. 
[8] Gulua, Ekaterine. (2013, March-April). Talent-Management - Actual Direction of Human Potential Management. "Economics and Business"- International Refereed and Reviewed Scientific and Practical Journal of the Faculty of Economics and Business, Ivane Javakhishvili Tbilisi State University, N2, , pp. 85-98

[9] Gulua, Ekaterine. (2017 fmols April-Jun). Modern Challenges of Higher Education. Economics and Business,Volume X, N2, Business and Economics Refereed and Reviewed International Scientific and Practical Journal of the Faculty of Economics and Business, Ivane Javakhishvili Tbilisi State University, pp. 112-132.

[10] Gulua, Ekaterine; Kharadze, Natalia. (2014). Knowledge-Based Organizational Culture Development Challenges in Small and Medium Sized Enterprises of Post-Soviet Georgia. 3rd International Symposium: "Advances in Busines Management Towards Systemic Approach" (pp. 93-96). Perugia: Business Systems Laboratory.

[11] Gulua, Ekaterine; Kharadze, Natalia;. (2017). Impact of Time Management on Personal Development of Master's Degree Students. ICSS XXIII, (pp. 110-118). Vienna.

[12] Gulua, Ekaterine; Kharadze, Natalia;. (2018). Organization Culture Management Challenges. European Journal of Interdisciplinary Studies , 67-79.

[13] Gulua, Ekaterine; Mikaberidze, Akaki. (2015). Exigency of Effective Cooperation between Higher Education Institutions and Business Organizations in Post Soviet Georgia. Proceedings of Multidisciplinary Academic Conference on Economics, Management and Marketing (pp. 7-11). Prague: EBSCO INFORMATION SERVICES.

[14] Gulua, Ekaterine;. (2011). The Ethical Management Issues in Organisation. Proceedings of the Scientific-

[15] Gulua, Ekaterine;. (2014). Globalization and Human Resource Management Challenges. Proceedings of IV International Conference: Globalization and Statistics, Ivane Javakhishvili Tbilisi State University (p. 153). Tbilisi: Universal.

[16] Kharadze, Natalia; Gulua, Ekaterine. (2016). Self Management Peculiarities of Master's Students in Georgia. Challenges of Globalızatıon İn Economıcs and Busıness (Pp. 613-616). Tbilisi: Universal.

[17] Kharadze, Natalia; Gulua, Ekaterine. (2017). Time Management Pecularities of Shota Rustaveli State University MA Students. Innovative Economics and Management , 20-25.

[18] Kharadze, Natalia; Gulua, Ekaterine. (2017). Time Management Peculiarities Based on Gender. I International Scientific and Practical Conference: Forsight-management: best world practice of development and integration of education, science and business (pp. 39-42). Kyiv-Tbilisi: Vyshemyrkyi.

[19] Kharadze, Natalia; Gulua, Ekaterine; Duglaze, Davit. (2017). Free-Time Management among Master's Degree Students of Georgia. ICSS XXIII, (pp. 24-33). Vienna.

[20] Kharadze, Natalia; Gulua, Ekaterine;. (2018). Organization Conflict Management Challenges. European Journal of Economics and Business Studies, 30-41.

[21] Kharadze, Natalia; Gulua, Ekaterine;. (2018, Volume 5). Analyze of Students' Attitude Survey of Professor Evaluation Criteria. Journal Innovative Economics and Management, pp. 122-131.

[22] Practical Conference Devoted to the 20th Anniversary of Kutaisi University: "Contemporary Problems of Economics and Business and Trends of Development", (pp. 54-57). Kutaisi. 